\begin{tabular}{lllll}
\hline Anthrop. Anz. & Jg. 66 & 2 & $139-146$ & Stuttgart, Juni 2008 \\
\hline
\end{tabular}

\title{
Craniometric measurements of artificial cranial deformations in Eastern European skulls
}

\author{
Wolfgang H. Arnold ${ }^{1}$, Victoria A. Fedorischeva ${ }^{2}$, Ella A. Naumova ${ }^{1}$ \\ and Nikolay I. Yabluchansky ${ }^{2}$ \\ ${ }^{1}$ Department of Anatomy, University of Witten/Herdecke, Witten, Germany \\ ${ }^{2}$ Faculty of Fundamental Medicine, Kharkov National University, Kharkov, Ukraine
}

With 3 figures and 2 tables

\begin{abstract}
Summary: Standardized lateral cephalograms of eleven skulls with artificial cranial deformations from Eastern Europe and twenty normal skulls from the same population were made, digitized and imported into the AutoCAD 2005 computer program. The $\mathrm{x}$ - and $\mathrm{y}$ coordinates of defined measuring points were determined and angle measurements were made. The form difference of the skulls was tested with the Euclidean Distance Matrix Analysis (EDMA) and the difference of the angle measurements were compared statistically using the non-parametric Mann-Whitney test. All deformed skulls belonged to the tabular fronto-occipital type of deformation. The results of the EDMA and the angle measurements indicated significant differences for the neurocranium and the facial cranium in height between the normal and the deformed skulls, but not in the cranial length. It can be concluded that in Eastern Europe one method of cranial molding was used. The deformation of the neurocranium also affected the development of the facial cranium regarding facial height. This may indicate a dependency of the developmental fields of the neurocranium and facial cranium.
\end{abstract}

Key words: Cranial deformation, geometric morphometry, X-ray analyses.

\section{Introduction}

The practice of intentional alteration of the head shape has been found from almost every geographic area of the world and may probably date back to approximately 45,000 BC, based upon Neanderthal skulls from the Shanidar cave in Iraq (Trinkaus 1982). For Homo sapiens it has been suggested that this practice became widespread throughout Asia and Eastern Europe with the movement of the Scythians towards Southern Russia and the Crimean peninsula in the $8^{\text {th }}$ and $7^{\text {th }}$ century BC (Schijman 2005). With the migration of the Huns towards Western Europe artificial head molding in newborns was carried to the whole of Central Europe and consequently artificially deformed skulls were found all over the European continent (Schijman 2005, Tubbs et al. 2006).

Besides tattooing, intentional scarring, piercing and teeth sharpening, intentional cranial deformation is another form of mutilation of the human body and associated with the cultural background of the society. It has been related to religion, to aestheticism and beauty, or to facilitate tribal identity. It has also been a symbol 